\title{
Transverse Micro Radiography Analysis of the Effect of Experimental Calcium-Containing Primer System on Demineralized Enamel
}

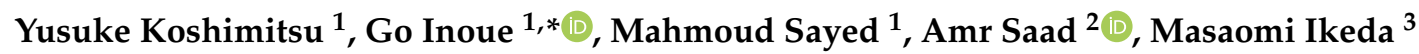 \\ and Junji Tagami ${ }^{1}$ \\ 1 Department of Cariology and Operative Dentistry, Division of Oral Health Sciences, Graduate School of \\ Medical and Dental Sciences, Tokyo Medical and Dental University (TMDU), 1-5-45 Yushima, Bunkyo-ku, \\ Tokyo 113-8549, Japan; koshimitsuyuusuke@gmail.com (Y.K.); drmahmoudmacklad@gmail.com (M.S.); \\ tagami.ope@tmd.ac.jp (J.T.) \\ 2 Department of Conservative Dentistry, Department of Clinical Dental Sciences, Batterjee Medical College of \\ Science \& Technology, North obhor, Jeddah 23815, Saudi Arabia; Amr.saad@bmc.edu.sa \\ 3 Department of Oral Prosthetic Engineering, Graduate School, Tokyo Medical and Dental \\ University (TMDU), 1-5-45 Yushima, Bunkyo-ku, Tokyo 113-8549, Japan; ikedsdt@tmd.ac.jp \\ * Correspondence: inoue.ope@tmd.ac.jp; Tel.: +81-3-5803-5483; Fax: +81-3-5803-0195
}

Received: 4 November 2020; Accepted: 23 November 2020; Published: 27 November 2020

check for updates

\begin{abstract}
Background: Enamel mineral density is dependent on a balanced dynamic process of demineralization and remineralization. Objective: We evaluated the remineralization potential of experimental calcium- containing primer $(\mathrm{CaP})$ application on enamel subsurface lesions. Methods: Demineralized enamel samples obtained from bovine incisor teeth were prepared and cut buccolingually. All samples were divided into 4 main groups according to the type of primer: CLEARFIL SE BOND 2 Primer (SEP), experimental calcium-containing primer (CaP) and bond: CLEARFIL SE BOND 2 Bond (SEB), CLEARFIL Protect Bond (PBB) treatment: (1) SEP-SEB (2) SEP-PBB (3) CaP-SEB (4) CaP-PBB. Each group was subdivided according to storage time in artificial saliva: immediately, 1 month and 6 months. Then, the samples were analyzed using transverse micro radiography (TMR). Additionally, the samples treated with each primer were prepared for scanning electron microscope (SEM) and energy dispersive X-ray spectroscopy (EDS) observation. Two-way ANOVA was used for the statistical analysis of mineral loss $(\Delta \mathrm{Z}: \mathrm{vol} \% \cdot \mu \mathrm{m})$. Results: CaP-PBB had the significantly lowest $\Delta \mathrm{Z}$ at all storage times, while SEP-SEB had the highest $\Delta \mathrm{Z}(p<0.05)$. SEM observations revealed that new crystals were formed on the surface after 6 months, and the ratio of calcium on the enamel increased in the EDS analysis. Conclusion: Experimental calcium-containing primer can provide additional mineral deposition, with even further deposition when combined with a fluoride-containing bond.
\end{abstract}

Keywords: remineralization; demineralized enamel; TMR; calcium containing primer; fluoride releasing materials

\section{Introduction}

Enamel is the hardest tissue in the human body. Enamel mineral density is regulated by a balanced dynamic process of demineralization and remineralization [1]. If this balance is lost and demineralization prevails, caries lesions can develop.

In the clinic, caries-infected dentin can be identified by using a caries dye detector [2]. However, in terms of enamel, there is no clear guideline for removing caries- infected enamel, which can lead to the presence of demineralized enamel remnants after cavity preparation. These remnants can cause a 
failure of adhesion to the enamel, with microleakages and weaker acid resistance at the interface of the restoration, potentially leading to secondary caries [3,4]. Farias de Lacerda AJ et al., reported that the microtensile bond strength to remineralized enamel is relatively equal to sound enamel, and is significantly higher than demineralized enamel substrate [5].

Fluoride-releasing materials (such as fluoride-releasing composite resins, glass ionomer cements, and bonding agents) have been investigated for many years. Fluoride in adhesive agents can significantly prevent secondary caries and does not reduce the microtensile bond strength [6-8].

On the other hand, materials that include calcium, such as Casein Phosphopeptide-Amorphous Calcium Phosphate (CPP-ACP) and Phosphoryl Oligosaccharides of Calcium (POs-Ca) can enhance the remineralization of enamel $[9,10]$, and in combination with fluoride can achieve the same effect in a short time [11]. However, no adhesive agent containing calcium has yet been found.

A calcium-containing primer adhesive system has been developed to provide minerals for demineralized dental tissue, with the aim of obtaining a stable adhesive interface, given caries-affected dentin has lower mechanical properties compared to sound dentin. This system has the potential to improve acid resistance and prevent secondary caries [12]. However to date, no review has demonstrated the effect of calcium-containing primer applied to enamel.

Therefore, the purpose of the present study was to evaluate the remineralizing ability of experimental calcium-containing primer with and without fluoride when bonded to demineralized enamel by TMR, to observe the changes in surface depositions using scanning electron microscope (SEM), and finally, to compare the elemental distribution on the surface by energy dispersive X-ray spectroscopy (EDS).

\section{Materials and Methods}

\subsection{Sample Preparation}

A total of 120 bovine enamel samples were used in this study. The enamel samples ( $0.5 \mathrm{~mm}$ thick) were obtained from the crown of bovine incisor teeth and cut buccolingually under proper water coolant with a low speed diamond saw (Isomet, Buehler, Lake Bluff, IL, USA). To flatten the surfaces of the samples, a series of silicon carbide papers (SiC) (600-1200 grit, Fuji Star, Sankyo Rikagaku, Saitama, Japan) were used under running water.

Then, an acid-resistant nail varnish (Revlon nail enamel, REVLON, Tokyo, Japan) was applied to the samples, leaving a $2 \times 2 \mathrm{~mm}^{2}$ window of exposed enamel. All samples were immersed in demineralization solution ( $2.2 \mathrm{mM} \mathrm{CaCl}_{2}, 2.2 \mathrm{mM} \mathrm{Na}_{2} \mathrm{HPO}_{4}, 50 \mathrm{mM}$ acetic acid; $\mathrm{pH}$ 5.0) for $96 \mathrm{~h}$ at $37^{\circ} \mathrm{C}$ to demineralize the enamel samples. The samples were then divided into two groups according to the primer used: 1. CLEARFIL SE BOND 2 Primer (SEP) (control), 2. experimental calcium containing Primer (CaP). This experimental primer was made by Kuraray Noritake Dental, Inc. (Tokyo, Japan) for this study. Each group was subdivided into 2 subgroups according to the type of bonding agent applied: 1. CLEARFIL SE BOND 2 Bond (SEB), 2. CLEARFIL Protect Bond (PBB) (Kuraray Noritake Dental), and thus, there were a total of 4 experimental groups (1) SEP-SEB (2) SEP-PBB (3) CaP-SEB (4) CaP-PBB (Table 1).

The experimental calcium-containing primer was prepared by adding $10 \mathrm{wt} \% \mathrm{CaCl}_{2}$ to CLEARFIL SE BOND 2 Primer. It was prepared as a two-bottle type primer to prevent the calcium from reacting with 10-MDP, allowing the calcium to exist in its ion form after mixing. The two bottles were mixed in equal proportions immediately before application to the enamel surface.

For the bonding procedures, the primer was applied to the enamel surface for $10 \mathrm{~s}$, after which the bonding agent was applied and light-cured for $10 \mathrm{~s}$ using a LED light-curing unit (VALO, $1000 \mathrm{~mW} / \mathrm{cm}^{2}$, standard mode, ULTRADENT JAPAN, Tokyo, Japan). Then, a $2 \mathrm{~mm}$-thick layer of resin composite (Clearfil Majesty ES flow, Shade A2, Kuraray Noritake Dental, Tokyo, Japan) was applied to the treated enamel surface and light-cured for $40 \mathrm{~s}$. Then, each experimental group was further divided according to storage time into immediately, 1 month, and 6 months storage terms $(n=10)$. The samples were then 
stored at $37^{\circ} \mathrm{C}$ in artificial saliva $\left(\mathrm{CaCl}_{2} 0.7 \mathrm{mmol} / \mathrm{L}, \mathrm{MgCl}_{2} \cdot 6 \mathrm{H}_{2} \mathrm{O} 0.2 \mathrm{mmol} / \mathrm{L}, \mathrm{KH}_{2} \mathrm{PO}_{4} 4.0 \mathrm{mmol} / \mathrm{L}\right.$, HEPES [Acid buffer] $20.0 \mathrm{mmol} / \mathrm{L}, \mathrm{KCl} 30.0 \mathrm{mmol} / \mathrm{Land} \mathrm{NaOH}$ to adjust the $\mathrm{pH}$ to 7.0 ).

Table 1. Materials used.

\begin{tabular}{|c|c|c|c|c|}
\hline & Code & Material & Composition & \\
\hline \multirow{3}{*}{ Primer } & SEP & $\begin{array}{l}\text { CLEAFIL SE BOND } 2 \\
\text { Primer }\end{array}$ & $\begin{array}{l}\text { MDP, HEMA, hydrophilic dimethacrylate, } \\
\text { water, initiator }\end{array}$ & $\mathrm{pH} 2.0$ \\
\hline & \multirow{2}{*}{$\mathrm{CaP}$} & $\begin{array}{l}\text { experimental calcium } \\
\text { containing primer }\end{array}$ & $\begin{array}{l}\text { Bottle A: MDP, HEMA, hydrophilic } \\
\text { dimethacrylate, water, initiator }\end{array}$ & \multirow{2}{*}{$\mathrm{pH} 2.4$} \\
\hline & & (2 Bottle) & Bottle B: $10 \mathrm{wt} \% \mathrm{CaCl}_{2}$, Water, HEMA & \\
\hline \multirow{2}{*}{ Bond } & SEB & $\begin{array}{l}\text { CLEARFIL SE BOND } 2 \\
\text { Bond }\end{array}$ & $\begin{array}{l}\text { MDP, Bis-GMA, HEMA, CQ, hydrophobic } \\
\text { dimethacrylate, N-diethanol-p-toluidine, } \\
\text { silanated colloidal silica }\end{array}$ & \\
\hline & PBB & CLEARFIL Protect Bond & $\begin{array}{l}\text { MDP, Bis-GMA, HEMA, CQ, hydrophobic } \\
\text { dimethacrylate, N,N-diethanol-p-toluidine, } \\
\text { silanated colloidal silica, surface-treated NaF }\end{array}$ & \\
\hline
\end{tabular}

MDP: 10-methacryloxydecyl dihydrogen phosphate, HEMA: 2-hydroxyethyl methacrylate, CQ: camphorquinone, Bis-GMA: 2,2-bis[4-(2-hydroxy-3-methacryloxy-propoxy)-phenyl]propane.

\subsection{Transverse Microradiography Analysis}

The experimental procedure for the transverse microradiography analysis (TMR) is shown in Figure 1.

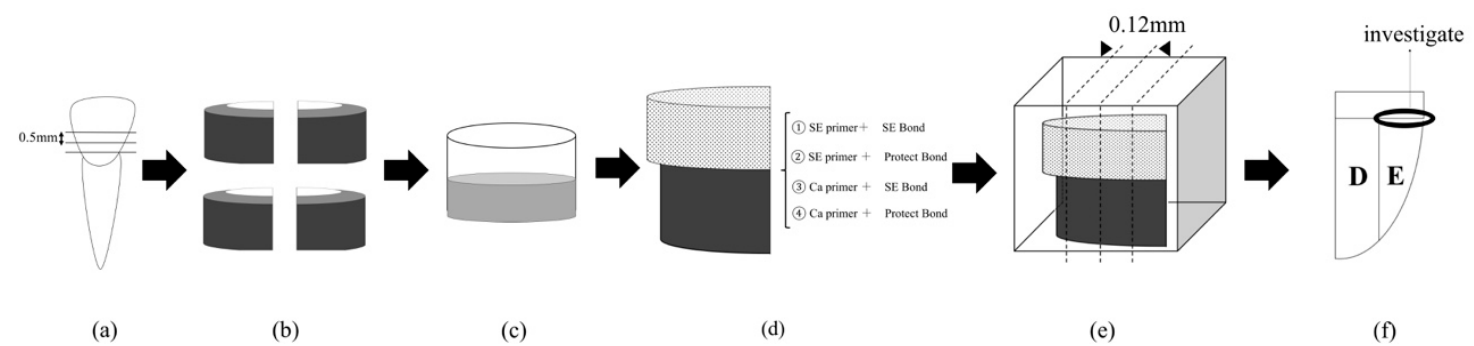

Figure 1. Preparation of enamel samples. (a) Obtain $0.5 \mathrm{~mm}$ enamel samples from bovine incisor teeth. (b) Divide into 2 parts from buccal to lingual and make a window $(2 \times 2 \mathrm{~mm})$ (c) Soak in demineralization solution for 4 days at $37^{\circ} \mathrm{C}$. (d) Apply adhesives to the four groups and build up resin composite. (e) Embed (epoxy resin), slice, and polish $(0.12 \mathrm{~mm})$ (f) Perform TMR analysis.

After storage, the samples were embedded in epoxy resin (GC Ostron RII, GC, Tokyo, Japan). In the "immediate" group, the storage time was $12 \mathrm{~h}$ from the bonding procedures, including the embedding time in the epoxy resin. Then, the samples were cut into approximately $120 \mu \mathrm{m}$-thick sections ( 2 sections/sample) using a low-speed diamond saw and silicon carbide papers ( $\mathrm{SiC}$ ) (600-1200-grit) under copious amounts of coolant. The obtained sections were placed along with a 15- step aluminum step-wedge on an X-ray glass plate (High Precision Photo Plate, Konica Minolta Photo, Tokyo, Japan). A soft X-ray generator SOFTEX CMR-2, Softex, Kanagawa, Japan) was used under the conditions of $20 \mathrm{kV}$ tube voltage, $2.5 \mathrm{~mA}$ tube current, and exposure time of $10 \mathrm{~min}$. An optical microscope (SMZ1000, Nikon, Tokyo, Japan) and CCD camera (DS-Fi1, Nikon, Tokyo, Japan) were used to digitally photograph the TMR images, an image analysis software (Image J, version 1.42q, Wayne Rasband, $\mathrm{NIH}$, Bethesda, MD, USA) was used to analyze the digitized images, and customized image processing software to calculate the mineral loss $(\Delta \mathrm{Z}: \mathrm{vol} \% \cdot \mu \mathrm{m})$. 


\subsection{Scanning Electron Microscopy and Energy Dispersive X-ray Spectrometry Analysis}

To observe the changes in the surface morphology, an additional 14 enamel samples were used for this test. The enamel samples $(0.05 \mathrm{~mm}$ thick) were prepared from the crown of bovine incisors by using a low-speed diamond saw (Isomet) under copious water coolant. Then, the surfaces of the enamel samples were immersed in demineralization solution and each primer was applied. Figure 2 showed the procedure for the SEM/EDS analysis. An SEM/EDS analysis was performed before the primer application, immediately, and after 1 month and 6 months of storage in artificial saliva $(n=2)$. Then, the samples were kept in a desiccator for $24 \mathrm{~h}$ and finally sputter-coated with platinum/gold coating. Because the coating for SEM makes the surface unsuitable for further storage or primer application, separate specimens were used for each primer and storage period group. To reduce variations in analysis of arch surface, SEM/EDS analysis was done in three points/sample (red circles). The surfaces were observed using SEM (JSM-IT 100, Joel Ltd., Tokyo, Japan) with energy dispersive X-ray spectroscopy (EDS). The specimens were analyzed with SEM under operating conditions of $20 \mathrm{KV}$.

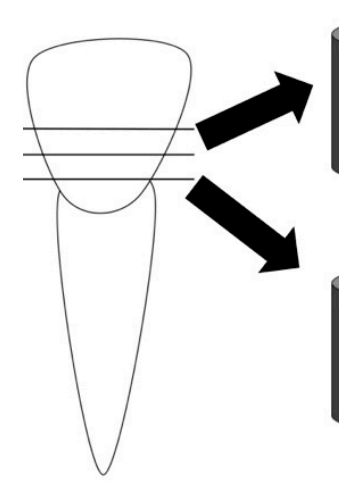

(a)

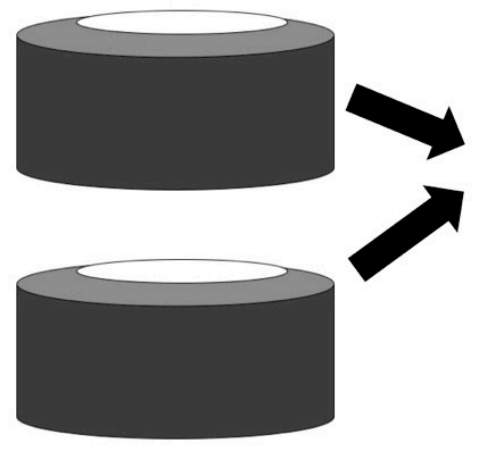

(b)

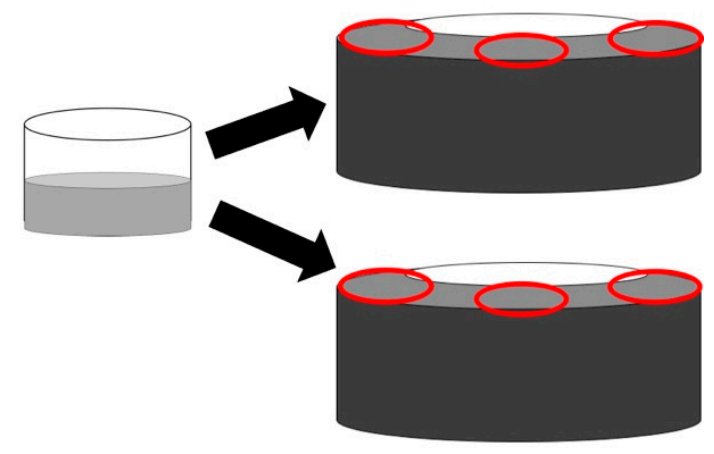

(c) (d)

Figure 2. Procedure for the SEM/EDS analysis.(a) Obtain enamel samples ( $0.05 \mathrm{~mm}$ thick) from bovine incisor teeth (b) Applying each primer (SEP, CaP) (c) Soak in artificial saliva (immediately, 1 month, 6 months) (d) Analyzing for 3 points (red circles).

\subsection{Statistical Analysis}

The effects on each group were analyzed by two-way ANOVA and t-test with Bonferroni correction at a significance level of $p<0.05$. Results were expressed as means \pm standard deviations. The statistical analysis was performed using IBM SPSS (SPSS Inc., IBM Corporation, New York, NY, USA), Version 23 for Windows.

\section{Results}

\subsection{TMR (Microradiography and Microdensitometries)}

TMR images and mineral profiles of the samples after each storage term (immediately after primer application (immediately, 1 month, and 6 months later) are shown in Figure 3.

The black curve shows the immediately group, the red curve shows the 1-month group, and the blue curve shows the 6-months group.

In all groups, the TMR analysis for the samples revealed a higher mineral deposition ability of CaP-PBB group by scoring the lowest mineral loss values $\Delta \mathrm{Z}$ (vol\%. $\mu \mathrm{m})$, followed by CaP-SEB group, SEP-PBB group and lastly SEP-SEB group, and significant difference was between the CaP-PBB group and SEP-SEB group at $p \leq 0.05$. However after 6 months, significant difference was not only between CaP-PBB group and SEP-SEB group, but also between CaP-PBB group and SEP-PBB group, and between CaP-SEB group and SEP-SEB group at $p \leq 0.05$ (Table 2). 
SEP-SEB

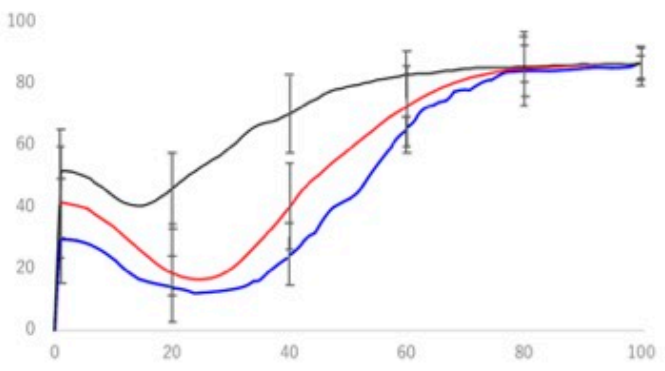

SEP-PBB

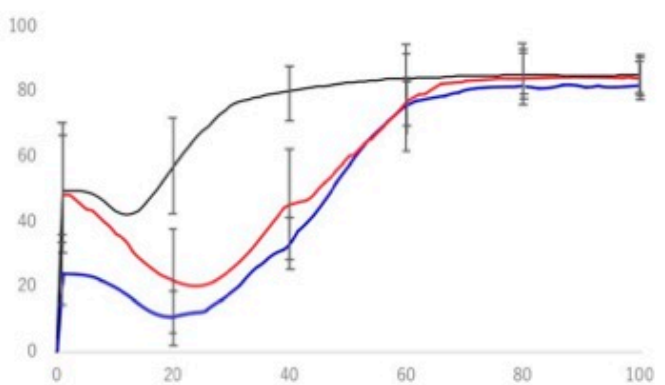

CaP-SEB

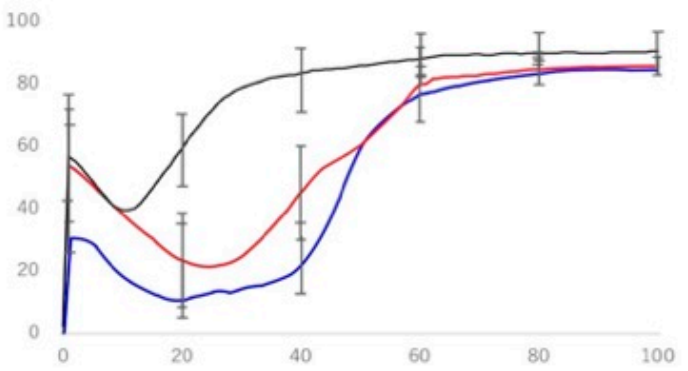

CaP-PBB

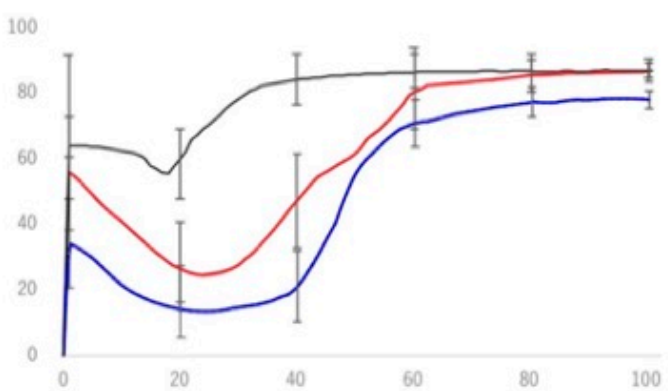

Figure 3. Average curve of mineral loss $(\Delta \mathrm{Z}) . \mathrm{X}$ axis is $\mu \mathrm{m}$. $\mathrm{Y}$ axis is $\mathrm{Vol} \%$.

Table 2. The mean value of mineral loss values $\Delta \mathrm{Z}$ ( $\mathrm{vol} \% . \mu \mathrm{m})$ at the 3 time points. Identical superscript letters indicate significant differences within each treatment period. $(p \leq 0.05)$.

\begin{tabular}{cccc}
\hline Group & Immediately & After 1 Month & After 6 Months \\
\hline SEP-SEB & $58.85 \pm 3.39 \mathrm{Aa}$ & $50.02 \pm 5.15^{\mathrm{Ba}}$ & $31.53 \pm 7.00^{\mathrm{Ca}}$ \\
SEP-PBB & $57.07 \pm 5.15^{\mathrm{Aa}}$ & $47.06 \pm 7.42^{\mathrm{Ba}}$ & $28.29 \pm 4.25^{\mathrm{Ca}}$ \\
CaP-SEB & $54.85 \pm 6.20^{\mathrm{Aa}}$ & $45.42 \pm 6.69^{\mathrm{Ba}}$ & $25.83 \pm 6.13^{\mathrm{Da}}$ \\
CaP-PBB & $53.49 \pm 6.34 \mathrm{Ab}$ & $42.90 \pm 9.33^{\mathrm{Bb}}$ & $22.31 \pm 4.77^{\mathrm{Dc}}$ \\
\hline
\end{tabular}

There was no significant difference between the same primer groups. The mineral loss of each pair of primer and bonding decreased significantly changing with time. Over time, each pair of primer and adhesive was decreasing significantly.

\subsection{Scanning Electron Microscope and Energy Dispersive X-Ray Analysis}

Figure 4 shows the SEM images of the enamel before and after using primers (SEP and CaP) at each storage time point. For the immediately group, the SEM images of the calcium-containing primer showed more surface depositions than SE primer (blue circle). After 1 month, the calcium-containing primer and SE primer were changed. Both SEM images of surface characters were coated by each primer and reacted with artificial saliva. There were no significant differences in the SEM images of each group. After 6 months, the SEM images of the SE primer were similar to that of the 1-month group. The calcium-containing primer of the 6-months group was obviously different from the others. The surface character of SEM images of the calcium-containing primer of the 6-months group were filled with crystals (red arrows).

The two pictures in the red rectangle are the same sample.

The EDS shows that the proportion of calcium increased throughout the storage time periods (Table 3). EDS data revealed a higher calcium proportion in the calcium- containing primer than in the CLEARFIL SE BOND 2 Primer at all storage time points. Over time, the proportion of calcium in each primer increased. 


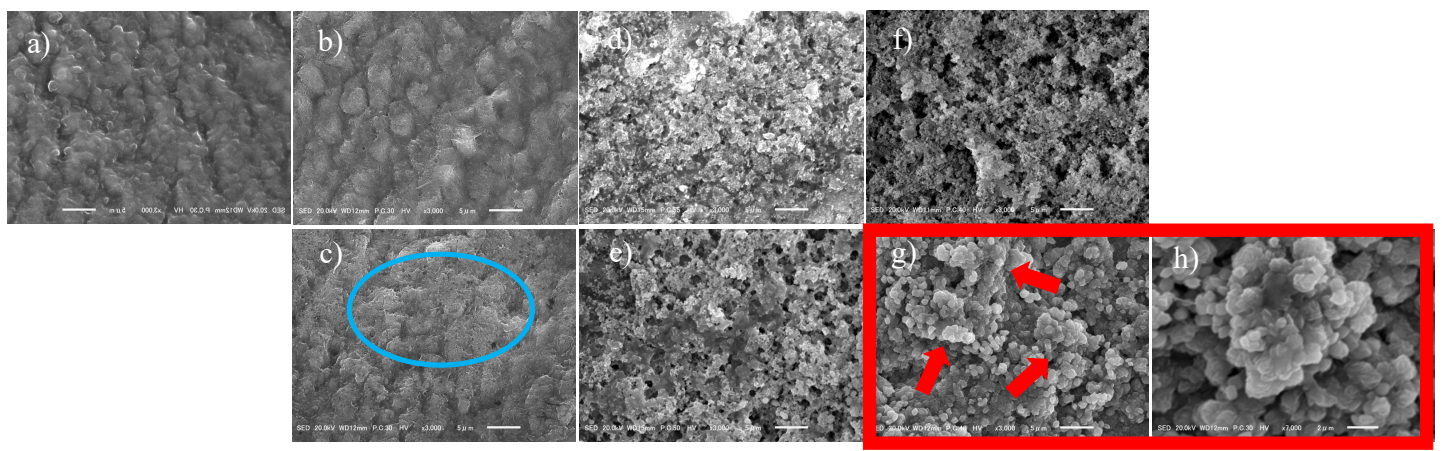

Figure 4. The SEM images before priming after using primer.(CLEARFIL SE BOND 2 Primer and experimental calcium-containing primer) at each storage time. (a) before priming $(\times 3000)$. (b) after CLEARFIL SE BOND 2 Primer of the immediately group $(\times 3000)$. (c) after experimental calcium containing primer of the immediately group $(\times 3000)$. (d) after CLEARFIL SE BOND 2 Primer of the 1 month storage time group $(\times 3000)$. (e) after experimental calcium containing primer of the 1 month storage group $(\times 3000)$. (f) after CLEARFIL SE BOND 2 Primer of the 6 months storage time group $(\times 3000)$. (g) after experimental calcium-containing primer of the 6 months storage group $(\times 3000)$. (h) higher magnification of $(\mathbf{g})(\times 7000)$.

Table 3. The mean value of rate (\%) of elemental composition before priming and at each storage time point after priming (immediately,1 month, and 6 months).

\begin{tabular}{cccccccc}
\hline & \multirow{2}{*}{$\begin{array}{c}\text { Before } \\
\text { Priming }\end{array}$} & \multicolumn{2}{c}{ Immediately Group } & \multicolumn{2}{c}{ 1 Month Storage Time } & \multicolumn{2}{c}{ 6 Months Storage Time } \\
\cline { 3 - 7 } & & SEP & CaP & SEP & CaP & SEP & CaP \\
\hline Calcium & $60.88 \pm 1.22$ & $61.01 \pm 2.24$ & $62.02 \pm 2.01$ & $63.11 \pm 1.99$ & $65.26 \pm 1.22$ & $64.66 \pm 2.34$ & $66.21 \pm 1.11$ \\
Phosphorous & $38.13 \pm 1.90$ & $36.56 \pm 1.76$ & $35.43 \pm 1.24$ & $34.14 \pm 0.99$ & $31.94 \pm 1.03$ & $32.57 \pm 1.67$ & $30.88 \pm 1.54$ \\
Chloride & $0.99 \pm 0.02$ & $2.43 \pm 0.02$ & $2.55 \pm 0.09$ & $2.75 \pm 0.12$ & $2.80 \pm 0.28$ & $2.77 \pm 0.20$ & $2.91 \pm 0.12$ \\
\hline
\end{tabular}

\section{Discussion}

In this study, bovine enamel was used, as many papers used bovine enamel instead of human enamel for demineralization studies invitro and rationales for using have been discussed previously [13]. Some human teeth have originally decalcified enamel, or clucks, in addition to the variability in the personal lifestyle (fluoride application, time of oral care and eating habits) which may give big bias during the experiment. In addition to being more consistent in terms of chemical composition, bovine teeth is more readily obtainable, and can produce larger and more flat samples [14-19].

The present study evaluated the effect of experimental calcium-containing primer on demineralized enamel surfaces by using TMR, SEM, and EDS. The TMR results showed less mineral loss $\Delta \mathrm{Z}$ (vol\% $\mu \mathrm{m})$ in experimental calcium-containing primer with and without Clearfil Protect Bond than the other primer/adhesive groups. Greater mineral deposition on the demineralized enamel surface after using an experimental calcium-containing primer was confirmed by the SEM/EDS analysis. This result indicates that experimental calcium-containing primer has the potential to increase enamel remineralization.

Mature enamel consists primarily of mineral components, hydroxyapatite (HA), as well as residual organic material and enamel fluid [20]. The structure of enamel is composed of enamel rods surrounded by rod sheaths with inter-rod (inter-prismatic) substances in between [21]. J.J.M Damen et al. reported that the formation of enamel subsurface lesions can easily be detected if the direction of demineralization is parallel to the enamel rods [22]. However, given that in this study we simulated proximal cavities, the direction of demineralization was perpendicular to the enamel rods. Hence, the subsurface lesions could not be seen clearly.

Ca-based products might suppress the demineralization process and enhance the remineralization of enamel through a continuous process of $\mathrm{Ca}^{+}$ion exchange $[23,24]$. The stepwise process of remineralization turns the latter into calcium octaphosphate (OCP), which then turns into HA [25]. Meanwhile, fluoride-containing adhesives are used for enhancing remineralization and reducing 
demineralization [26], where $\mathrm{F}$ ions are released from the adhesive and are incorporated into the tooth structure, leading to the formation of fluorapatite [27]. Fluorapatite has greater chemical stability and acid resistance than HA [4]. The combination of Ca-containing primer and F-containing adhesive is likely to have additive or synergistic effects. The $\mathrm{F}$ ions released from the bonding agent might react with the $\mathrm{Ca}$ ions within the media to form a calcium fluoride $\left(\mathrm{CaF}_{2}\right)$ compound, which precipitates on the surface of enamel lesions and acts as a source of minerals for remineralization [28]. The TMR analysis for the CaP-PBB group recorded the lowest mineral loss at all time points. Moreover, the SEM/EDS analysis presented the precipitation on the enamel surface with a high percentage of calcium. Both results support the above hypothesis. However, SEM/EDS analysis is not able to detect the amount of each ion accurately, and molecules in the crystal. Further analysis will be needed.

In our study, the SEP-SEB group had the highest mineral loss values at all time points in the TMR analysis, and presented the lowest Ca content compared with the other groups using the SEM/EDS analysis. Thus, this group had the lowest ability for remineralization among all the groups.

The TMR results also revealed that the CaP-SEB group had less mineral loss than the SEP-SEB group after 6 months. A portion of $\mathrm{Ca}$ ions from the Ca-containing primer reacted to the remineralization process of the demineralized enamel surface, and the others might react with MDP to form Ca/MDP salts [29]. These salts can precipitate on the demineralized enamel surface, acting as a source of $\mathrm{Ca}$ ions to promote remineralization over time [30]. In addition, the CaP-SEB group showed less mineral loss than the SEP-PBB group, which implies that $\mathrm{Ca}$ ions have a greater effect on mineral generation than $\mathrm{F}$ ions.

Regarding the time intervals in $\triangle \mathrm{Z}$ of the TMR results, the immediately group and the 1 month later group showed significant differences between CaP-PBB and SEP-SEB, yet the 6 months later group showed some differences (between CaP-PBB and SEP-SEB, between CaP-PBB and SEP-PBB, and between CaP-SEB and SEP-SEB). These results imply that the Ca from the primer affects mineral deposition on the demineralized mineral over time. Compared with the other primer (control), there was no significant difference between any storage time intervals.

In the SEM analysis, only 6 months of storage showed crystal formations on the surface in the sample treated with a Ca-containing primer. EDS also recorded a high Ca ratio on the surface of the sample. It can be assumed that $\mathrm{Ca}$ from the primer reacted with the phosphate in the artificial saliva or MDP of the primer, generating monocalcium salts or some sort of Ca precipitate. These crystals present good stability [31,32]. However, it should be mentioned that despite the small relative standard deviations in the EDS analysis, the individual structural differences between each sample and point of analysis may have an influence on the EDS readings.

Based on the TMR results, calcium-containing primer alone had a greater effect over time, and the precipitate after treatment with a calcium-containing primer could be key to improving remineralization. During clinical placement, a firm adhesive is needed between the enamel/dentin and the restorative material. Using bonding agents leads to the formation of a hybrid layer and an acid-base resistant zone beneath the dentin, which can prevent secondary caries. Also, a thicker zone can be formed when bonded to caries-affected dentin [33]. If the precipitate observed in this study can improve bonding strength, a new strategy for inhibiting secondary caries in both enamel and dentin needs to be established. However there are lack of several individual factors which may affect potential impact on remineralization (e.g., $\mathrm{pH}$ cycles, acid challenges after bonding, continuous fluid movement, stimulation of salivary flow) [34-36]. Further studies are warranted to elucidate the character of the precipitates and to simulate the oral conditions.

\section{Conclusions}

Experimental calcium-containing primer as an adhesive improved mineral density in demineralized enamel and, in combination with fluoride-containing adhesive, further improved mineral density. We suggest that using experimental calcium-containing primer itself has a remineralization effect on demineralized enamel surfaces. 
Author Contributions: Y.K.: conceptualization, Methodology, Investigation, Drafting the article. G.I.: conceptualization, Methodology, revising the article. M.S.: Methodology, Investigation, revising the article. A.S.: Revising the article. M.I.: data analysis and statistics. J.T.: conceptualization and Revising the article. All authors have read and agreed to the published version of the manuscript.

Funding: This research received no external funding.

Acknowledgments: We would like to thank KURARAY NORITAKE DENTAL Inc. for their contribution of the required materials in this study.

Conflicts of Interest: The authors declare no conflict of interest.

\section{References}

1. Aoba, T. Solubility properties of human tooth mineral and pathogenesis of dental caries. Oral Dis. 2004, 10, 249-257. [CrossRef] [PubMed]

2. Kuboki, Y.; Liu, C.F.; Fusayama, T. Mechanism of differential staining in carious dentin. J. Dent. Res. 1983, 62, 713-714. [CrossRef] [PubMed]

3. Jokstad, A. Secondary caries and microleakage. Dent. Mater. 2016, 32, 11-25. [CrossRef]

4. Pinto, C.F.; Paes-Leme, A.F.; Ambrosano, G.M.; Giannini, M. In vitro secondary caries inhibition by adhesive systems in enamel around composite restorations. Oper. Dent. 2010, 35, 345-352. [CrossRef]

5. De Lacerda, F.A.J.; Ferreira Zanatta, R.; Crispim, B.; Borges, A.B.; Gomes Torres, C.R.; Tay, F.R.; Pucci, C.R. Influence of de/remineralization of enamel on the tensile bond strength of etch-and-rinse and self-etching adhesives. Am. J. Dent. 2016, 29, 289-293.

6. Hara, A.T.; Turssi, C.P.; Ando, M.; González-Cabezas, C.; Zero, D.T.; Rodrigues, A.L.; Serra, M.C.; Cury, J.A. Influence of fluoride-releasing restorative material on root dentine secondary caries in situ. Caries Res. 2006, 40, 435-439. [CrossRef]

7. Amaechi, B.T.; Van Loveren, C. Fluorides and non-fluoride remineralization systems. Monogr. Oral Sci. 2013, 23, 15-26. [CrossRef] [PubMed]

8. Fontana, M. Enhancing Fluoride: Clinical Human Studies of Alternatives or Boosters for Caries Management. Caries Res. 2016, 50 (Suppl. 1), 22-37. [CrossRef]

9. Kitasako, Y.; Sadr, A.; Hamba, H.; Ikeda, M.; Tagami, J. Gum containing calcium fluoride reinforces enamel subsurface lesions in situ. J. Dent. Res. 2012, 91, 370-375. [CrossRef]

10. Hamba, H.; Nikaido, T.; Inoue, G.; Sadr, A.; Tagami, J. Effects of CPP-ACP with sodium fluoride on inhibition of bovine enamel demineralization: A quantitative assessment using micro-computed tomography. J. Dent. 2011, 39, 405-413. [CrossRef]

11. Sugiura, M.; Kitasako, Y.; Sadr, A.; Shimada, Y.; Sumi, Y.; Tagami, J. White spot lesion remineralization by sugar-free chewing gum containing bio-available calcium and fluoride: A double-blind randomized controlled trial. J. Dent. 2016, 54, 86-91. [CrossRef] [PubMed]

12. Ochiai, Y.; Inoue, G.; Nikaido, T.; Ikeda, M.; Tagami, J. Evaluation of experimental calcium-containing primer in adhesive system on micro-tensile bond strength and acid resistance. Dent. Mater. J. 2019, 38, 565-572. [CrossRef] [PubMed]

13. Lynch, R.J.M. Model parameters and their influence on the outcome of in vitro demineralisation and remineralisation studies. Monogr. Oral Sci. 2006, 19, 65-85. [CrossRef]

14. Kielbassa, A.M.; Shohadai, S.P.; Schulte-Mönting, J. Effect of saliva substitutes on mineral content of demineralized and sound dental enamel. Support Care Cancer 2001, 9, 40-47. [CrossRef] [PubMed]

15. Kielbassa, A.M.; Hellwig, E.; Meyer-Lueckel, H. Effects of irradiation on in situ remineralization of human and bovine enamel demineralized in vitro. Caries Res. 2006, 40, 130-135. [CrossRef]

16. Van der Reijden, W.A.; Buijs, M.J.; Damen, J.J.; Veerman, E.C.; ten Cate, J.M.; Nieuw Amerongen, A.V. Influence of polymers for use in saliva substitutes on de- and remineralization of enamel in vitro. Caries Res. 1997, 31, 216-223. [CrossRef]

17. Amaechi, B.T.; Higham, S.M.; Edgar, W.M. Use of transverse microradiography to quantify mineral loss by erosion in bovine enamel. Caries Res. 1998, 32, 351-356. [CrossRef]

18. Shu, M.; Wong, L.; Miller, J.H.; Sissons, C.H. Development of multi-species consortia biofilms of oral bacteria as an enamel and root caries model system. Arch. Oral Biol. 2000, 45, 27-40. [CrossRef] 
19. Tschoppe, P.; Kielbassa, A.M.; Meyer-Lueckel, H. Evaluation of the remineralizing capacities of modified saliva substitutes in vitro. Arch Oral Biol. 2009, 54, 810-816. [CrossRef]

20. Bartlett, J.D. Dental enamel development: Proteinases and their enamel matrix substrates. ISRN Dent. 2013, 2013, 684607. [CrossRef]

21. Schmitz, J.E.; Teepe, J.D.; Hu, Y.; Smith, C.E.; Fajardo, R.J.; Chun, Y.H. Estimating mineral changes in enamel formation by ashing/BSE and microCT. J. Dent. Res. 2014, 93, 256-262. [CrossRef] [PubMed]

22. Damen, J.J.; Exterkate, R.A.; Ten Cate, J.M. Reproducibility of TMR for the determination of longitudinal mineral changes in dental hard tissues. Adv. Dent. Res. 1997, 11, 415-419. [CrossRef] [PubMed]

23. Tung, M.S.; Eichmiller, F.C. Amorphous calcium phosphates for tooth mineralization. Compend. Contin. Educ. Dent. 2004, 25, 9-13. [PubMed]

24. Dewani, N.; Kashyap, N.; Avinash, A.; Kumar, B.; Singh, M.; Pawar, P. Effect of casein phosphopeptideamorphous calcium phosphate as a remineralizing agent-An In Vivo study. Indian J. Dent. Res. 2019, 30, 820-825. [CrossRef]

25. Shen, P.; Walker, G.D.; Yuan, Y.; Reynolds, C.; Stanton, D.P.; Fernando, J.R.; Reynolds, E.C. Importance of bioavailable calcium in fluoride dentifrices for enamel remineralization. J. Dent. 2018, 78, 59-64. [CrossRef]

26. Kalashnikov, D.V.; Hasiuk, P.A.; Vorobets, A.B.; Rosolovska, S.O.; Kindiy, D.D.; Hrad, A.O.; Zubchenko, S.G. Features of the course of enamel biomineralization processes in various anatomical areas of the tooth. Wiad Lek. 2020, 73, 864-867. [CrossRef]

27. Pajor, K.; Pajchel, L.; Kolmas, J. Hydroxyapatite and Fluorapatite in Conservative Dentistry and Oral Implantology-A Review. Materials 2019, 12, 2683. [CrossRef]

28. Cardoso, C.A.B.; Lacerda, B.; Mangueira, D.F.B.; Charone, S.; Olympio, K.P.; Magalhães, A.C.; Pessan, J.P.; Vilhena, F.V.; Sampaio, F.C.; Buzalaf, M.A.R. Mechanisms of action of fluoridated acidic liquid dentifrices against dental caries. Arch. Oral Biol. 2015, 60, 23-28. [CrossRef]

29. Fukegawa, D.; Hayakawa, S.; Yoshida, Y.; Suzuki, K.; Osaka, A.; Van Meerbeek, B. Chemical interaction of phosphoric acid ester with hydroxyapatite. J. Dent. Res. 2006, 85, 941-944. [CrossRef]

30. Li, X.; Wang, J.; Joiner, A.; Chang, J. The remineralisation of enamel: A review of the literature. J. Dent. 2014, 42 (Suppl. 1), S12-S20. [CrossRef]

31. Yaguchi, T. Layering mechanism of MDP-Ca salt produced in demineralization of enamel and dentin apatite. Dent. Mater. 2017, 33, 23-32. [CrossRef] [PubMed]

32. Yokota, Y.; Nishiyama, N. Determination of molecular species of calcium salts of MDP produced through decalcification of enamel and dentin by MDP-based one-step adhesive. Dent. Mater. J. 2015, 34, 270-279. [CrossRef] [PubMed]

33. Inoue, G.; Tsuchiya, S.; Nikaido, T.; Foxton, R.M.; Tagami, J. Morphological and mechanical characterization of the acid-base resistant zone at the adhesive-dentin interface of intact and caries-affected dentin. Oper. Dent. 2006, 31, 466-472. [CrossRef] [PubMed]

34. Peters, M.C. Strategies for noninvasive demineralized tissue repair. Dent. Clin. N. Am. 2010, 54, 507-525. [CrossRef] [PubMed]

35. Duke, S.A.; Forward, G.C. The conditions occurring in vivo when brushing with toothpastes. Br. Dent. J. 1982, 152, 52-54. [CrossRef] [PubMed]

36. Kielbassa, A.M.; Muller, J.; Gernhardt, C.R. Closing the gap between oral hygiene and minimally invasive dentistry: A review on the resin infiltration technique of incipient (proximal) enamel lesions. Quintessence Int. 2009, 40, 663-681.

Publisher's Note: MDPI stays neutral with regard to jurisdictional claims in published maps and institutional affiliations.

(C) 2020 by the authors. Licensee MDPI, Basel, Switzerland. This article is an open access article distributed under the terms and conditions of the Creative Commons Attribution (CC BY) license (http://creativecommons.org/licenses/by/4.0/). 